Artigo original

Hegemonia - Revista Eletrônica do Programa de Mestrado em Direitos Humanos, Cidadania e Violência/Ciência Política do Centro Universitário Unieuro

ISSN: 1809-1261

UNIEURO, Brasília, número 26, Janeiro a Junho de 2019, pp. 152-173.

Recebido em: 23/05/2018

Avaliado em: 15/07/2018

Aprovado em: 10/09/2018

\title{
O PAPEL DOS GOVERNOS LOCAIS NA MANUTENÇÃO DA DEMOCRACIA: UMA ANÁLISE A PARTIR DE MOÇAMBIQUE
}

Jochua Abrão Baloi ${ }^{1}$

Resumo: O objetivo deste artigo é analisar o papel dos Governos Locais na manutenção da democracia, tomando como ponto de partida a realidade moçambicana. Nele argumenta-se que os Governos Locais são os catalisadores essenciais não só para a manutenção da democracia como também para a consolidação da paz. Esta premissa é secundada por vários fatores ligados ao seu surgimento, como sejam: a implantação da nova Constituição de 1990, a assinatura do Acordo Geral de Paz em Roma (1992) que deu fim à guerra civil, as primeiras eleições democráticas e multipartidárias de outubro de 1994, a inculcação da lei 2/97, que cria o quadro jurídico legal para a implantação das autarquias locais. Estes fatores foram determinantes para a criação dos Governos Locais, que são de fato e de júri instrumentos fundamentais na manutenção da democracia em Moçambique. Não obstante a capacidade dos Governos Locais de proverem serviços sociais universais e de aumentarem as formas de democracia participativa, através da competição eleitoral, da legitimidade das eleições e da participação política, que aconteceu nas 4 eleições dos governos locais, alguns municípios vêm assumido novos papeis na liderança democrática como resultado da política da Descentralização em Moçambique.

Palavras-Chave: Democracia, Governos Locais, Descentralização, Moçambique.

${ }^{1}$ Doutorando em Ciência Política no Instituto de Estudos Sociais e Políticos da Universidade do Estado do Rio de Janeiro (IESP-UERJ). 
Artigo original

Hegemonia - Revista Eletrônica do Programa de Mestrado em Direitos Humanos, Cidadania e Violência/Ciência Política do Centro Universitário Unieuro

ISSN: 1809-1261

UNIEURO, Brasília, número 26, Janeiro a Junho de 2019, pp. 152-173.

Abstract: This article comes about with the objective of analyzing the role of Local Governments in the maintenance of democracy, taking as a starting point the Mozambican reality. It is argued that, the Local Governments are the essential catalysts not only for the maintenance of democracy but also for the consolidation of the peace. This premise is supported by several factors linked to its emergence, such as the implementation of the new Constitution of 1990, the signing of the General Peace Agreement in Rome (1992), which ended the civil war, the first democratic and multiparty elections in October 1994, the inculcation of Law 2/97, which creates the legal framework for the implementation of local authorities. These factors were decisive for the creation of the Local Governments, which are de jure and de facto fundamental instruments for the maintenance of democracy in Mozambique. Notwithstanding the ability of Local Governments to provide universal social services and to increase forms of participatory democracy, through electoral competition, electoral legitimacy and political participation, which took place in the 4 local government elections, some municipalities have assumed new roles in democratic leadership as result of Decentralization in Mozambique.

Keywords: Democracy, Local Governments, Decentralization, Mozambique.

Introdução

O presente artigo põe em pauta uma discussão recorrente na academia, na opinião pública, e também na população em geral, sobre a pertinência dos Governos Locais na consolidação da Descentralização e pretende analisar o papel destes na manutenção da democracia, tomando como ponto de partida a realidade moçambicana. Depois da proclamação da independência nacional e fundação do Estado em 1975, eclodiu uma guerra civil, desencadeada pela Renamo², em 1977 contra o governo de Moçambique, que veio a terminar em 1992 com a assinatura do Acordo Geral de Paz em Roma, antecedida por uma revisão constitucional em 1990, que abriu espaço para a democracia multipartidária.

2 Resistência Nacional de Moçambique, movimento armado fundado em finais da década de 1970 por André Machangaissa que se opôs aos ideais da Frelimo acabando por desencadear uma guerra civil de 16 anos entre 1977 a 1992. Hoje em dia é o maior partido da oposição com assento no parlamento. 
Artigo original

Hegemonia - Revista Eletrônica do Programa de Mestrado em Direitos Humanos, Cidadania e Violência/Ciência Política do Centro Universitário Unieuro

ISSN: 1809-1261

UNIEURO, Brasília, número 26, Janeiro a Junho de 2019, pp. 152-173.

Moçambique é um país unitário, democrático e descentralizado, onde só são eleitos através do sufrágio universal, o Presidente da República e o governo local, os outros órgãos locais do Estado, é o caso do governador, do administrador, do chefe do posto administrativo são nomeados pelo governo central sob proposta do Ministério da Administração Estatal e Função Pública. Destarte, os Governos Locais são pessoas coletivas públicas, dotadas de órgãos representativos próprios, que visam à prossecução dos interesses das populações respetivas, sem prejuízo dos interesses nacionais e da participação do Estado. Por conseguinte, eles foram criados com o ensejo de garantir aos cidadãos o bem-estar, a melhoria da renda e da qualidade da sua vida, o que só era fatível através do desenvolvimento dos serviços em cada comunidade. Sendo assim, eles são importantes no desenvolvimento local e são um catalisador fundamental na legitimação do poder, onde fazem aproximação dos cidadãos nos centros de tomada de decisão e no aprofundamento da democracia.

Um dos problemas que Moçambique enfrenta concernente à governação local é a questão da Descentralização administrativa, que se assenta na necessidade de redução dos poderes administrativos dos órgãos centrais, atribuindo a decisão aos órgãos locais. Portanto, tendo em vista o exposto acima, o argumento geral desta pesquisa é que os governos locais são catalisadores essenciais na manutenção da democracia e da paz em Moçambique.

A construção metodológica que norteia este artigo comporta uma simbiose de vários métodos (Qualitativo, Monográfico, Histórico, Bibliográfico), aliando-os ao hermenêutico-reflexivo para o alcance efetivo do referencial teórico e histórico do papel dos governos locais na manutenção da democracia. Este trabalho está dividido em três partes, além da introdução e conclusão. Na primeira, apresenta-se o contexto do surgimento dos Governos Locais em Moçambique; em seguida debata-se o papel dos governos locais no contexto da governação em Moçambique, e por fim apresenta-se uma leitura crítico-reflexiva das 4 eleições dos Governos Locais que Moçambique teve até hoje. 
Artigo original

Hegemonia - Revista Eletrônica do Programa de Mestrado em Direitos Humanos, Cidadania e Violência/Ciência Política do Centro Universitário Unieuro

ISSN: 1809-1261

UNIEURO, Brasília, número 26, Janeiro a Junho de 2019, pp. 152-173.

\section{Contexto do Surgimento dos Governos Locais em Moçambique}

Não são muitos os estudos que se concentram no estudo sobre os Governos Locais ${ }^{3}$ em Moçambique, principalmente para relacioná-los com a manutenção da democracia. Neste sentido, a maior parte da abordagem deste tema, o foco de análise é quase ao nível da esfera nacional. Entretanto, a abordagem dos governos locais está longe de ser irrelevante para o sistema democrático moçambicano.

Em todos os países descentralizados, a democracia acontece como um processo que se constrói de forma permanente e deve-se assentar no ideal da partilha do poder entre os atores políticos através do processo de participação política dos cidadãos na tomada de decisão. Neste sentido, seja qual for o contexto em que se desenvolve o processo da democratização, sempre existe uma possibilidade de se criar instituições e/ou órgãos tanto nacionais como locais para garantir a operacionalização dos desígnios do projeto democrático através do processo de delegação de poderes, que se legitimam pelo sufrágio universal, em função de se deslocar o poder do topo para a base.

No contexto moçambicano, esta deslocação do poder do topo para a base ou do centro para a periferia, está plasmado no $n^{\circ} 1$ do artigo $263^{\circ}$ da Constituição da República de 2004, que prevê que “a organização e o funcionamento dos órgãos do Estado a nível local obedecem aos princípios de Descentralização e desconcentração, sem prejuízo da unidade de ação e dos poderes de direção do Governo".

A despeito da Descentralização, o Governo central de Moçambique atribui aos órgãos locais (Vilas e Cidades) o poder de administrar o território sob sua jurisdição, acontecendo neste sentido, a

\footnotetext{
${ }^{3}$ Neste artigo, os termos Governos Locais, Autarquias Locais, Órgãos do Poder Local, Poder Local foram usados como sinônimos.
} 
Artigo original

Hegemonia - Revista Eletrônica do Programa de Mestrado em Direitos Humanos, Cidadania e Violência/Ciência Política do Centro Universitário Unieuro

ISSN: 1809-1261

UNIEURO, Brasília, número 26, Janeiro a Junho de 2019, pp. 152-173.

partilha de responsabilidades e autoridades entre o governo central e os órgãos locais do Estado ${ }^{4}$ por forma a responder da melhor maneira possível às necessidades dos cidadãos residentes nesses lugares.

Na perspectiva de Faria e Chichava (1999: 4), Moçambique tal como outros países da região ${ }^{5}$, iniciou um processo de Descentralização que é parte integrante de um conjunto de reformas e mudanças de natureza política ${ }^{6}$, econômica e administrativa em curso desde os anos 80, e tornadas praticamente inevitáveis pela contínua degradação da situação econômica, social e política em que Moçambique atravessava.

Apesar de a Descentralização em Moçambique remontar a sua existência desde o período colonial, a partir da divisão administrativa do país em províncias, distritos, municípios e postos administrativos, onde cada nível de divisão administrativa se subordinada à anterior numa estrutura hierarquicamente definida, funcionando com base no poder popular instituído, neste período, ela nunca funcionou de fato, posto que, o poder de decisão cabia em última instância ao partido único, a Frelimo $^{7}$, cuja estrutura era já em si muito centralizadora desde o alcance da independência_Weimar

\footnotetext{
${ }^{4}$ Os Órgãos do Estado localmente representados recebem continuamente, a cada nível, competências e meios de modo a aproximar a decisão aos locais de sua aplicação. Na sua atuação estes órgãos realizam as funções em estreita ligação com os órgãos representativos das populações em conformidade com a Lei 8/2003 de 19 de maio.

${ }^{5}$ É o caso de África do Sul, Zimbabwe, Namíbia, Botswana, Angola, República Democrática de Congo, Malawi, Zâmbia, Tanzânia.

6 Nestes países da SADC (Comunidade para o Desenvolvimento da África Austral e do Inglês, Southern Africa Development Community), houve sobremaneira este conjunto de reformas e mudanças de natureza política, posto que na altura, o contexto sócio-político e econômico, a administração pública destes países se mostrava quase ineficiente e inoperante, apresentando graves problemas ligados à incapacidade ao nível da gestão dos recursos humanos e financeiros do Estado. Esta situação causou algumas querelas de responsabilidades e ilegitimidade destes países para responder a qualquer problema que afligia ao cidadão. Foi nesse sentido que surgiu o processo da Descentralização concomitante nestes países.

${ }^{7}$ Frente de Libertação de Moçambique, que é o partido no poder, foi fundado em 1962 na Tanzânia por Eduardo Mondlane, como um movimento revolucionário. Este movimento revolucionário uniu vários movimentos de cariz nacionalista e liderou a luta de libertação de Moçambique, contra o colonialismo Português. Com a proclamação da Independência Nacional a 25 de junho de 1975 encabeçou a liderança do governo de transição e dos governos seguintes, transformando-se em partido político em 1977.
} 
Artigo original

Hegemonia - Revista Eletrônica do Programa de Mestrado em Direitos Humanos, Cidadania e Violência/Ciência Política do Centro Universitário Unieuro

ISSN: 1809-1261

UNIEURO, Brasília, número 26, Janeiro a Junho de 2019, pp. 152-173.

\& Fandrych, 1998; Faria \& Chichava, 1999). Ela só funcionou de fato e de júri, a partir da concepção da lei 3/94, que aprovava o quadro institucional dos distritos municipais, posteriormente revogada pela lei 2/97, que aprova o quadro jurídico para implantação das Autarquias Locais em Moçambique.

Destarte, a constituição de 1990 que é sucedânea da revisão geral da de 1975, mudou todo o percurso dos sectores que se ligam à gestão do país, sendo que introduziu o multipartidarismo como sistema político vigente; introduziu a inserção efetiva da democracia representativa e participativa, legitimando o papel dos partidos políticos no alcance da democracia; o Estado assumiu a função de reguladora e controladora, quer dizer, previsão de mecanismos da economia do mercado, deixando de lado o papel de Estado gestor e intervencionista. Houve, de facto, no Estado Moçambicano, a criação do Conselho Constitucional que seria o garante da constitucionalidade e da legalidade. Estas mudanças foram o prelúdio da inculcação da democracia em Moçambique.

Em outubro de 1994, dando continuidade ao preceituado na Constituição de 1990 que criava o multipartidarismo, o país teve as primeiras eleições presidenciais, gerais e democráticas. Sendo assim, a Descentralização teve impacto notável com o fim do poder de decisão monopartidário, que levou Moçambique a optar pelo pluripartidarismo. Portanto, como corolário desta democracia, em 1996, por meio de uma emenda constitucional, deu-se lugar às Autarquias Locais ou Governos Locais como pessoas coletivas públicas, dotadas de órgãos representativos próprios.

A instituição dos Governos Locais em Moçambique tinha como intuitos: criar um bem-estar e melhorar a renda e a qualidade de vida dos cidadãos, o que se efetivou através do desenvolvimento econômico local; prestação de melhores serviços em cada comunidade, que isto dependeria dos recursos gerados e disponíveis nas respetivas comunidades, e desenvolver os serviços urbanos em relação direta com o aumento de receitas autárquicas, pelo que a prioridade seria dada à área do desenvolvimento local nas autarquias.

Em Moçambique, o processo da Descentralização foi 
Artigo original

Hegemonia - Revista Eletrônica do Programa de Mestrado em Direitos Humanos, Cidadania e Violência/Ciência Política do Centro Universitário Unieuro

ISSN: 1809-1261

UNIEURO, Brasília, número 26, Janeiro a Junho de 2019, pp. 152-173.

no geral fortemente apoiado pelos doadores $^{8}$, e sofreu a priori grandes alterações desde o seu início até à realização, em Junho de 1998, das primeiras eleições autárquicas, limitadas a 33 municípios ${ }^{9}$, incluindo as autoridades tradicionais no processo de consulta e tomadas de decisões locais particularmente em questões relacionadas com o uso da terra e abrangendo consequentemente apenas uma pequena parte da população moçambicana de acordo com o gradualismo que o governo imprimiu ao processo (FERNANDES, 2009:116).

Face aos resultados das primeiras eleições autárquicas, marcadas por uma elevada taxa de abstenção e boicotadas pela oposição, a atitude mais ou menos generalizada (por parte do governo, oposição e doadores) era de repensar no processo. Por parte dos doadores, tratava-se nomeadamente de repensar os apoios à Descentralização e de promover novas abordagens que permitissem uma maior participação, envolvimento e capacitação de todos os atores responsáveis ou envolvidos no processo.

O processo da Descentralização em Moçambique pressupõe que cada cidadão colabore com o seu talento, com a sua capacidade, com o sentido de responsabilidade para a unicidade do Estado, e que a gestão da coisa pública deveria ser efetiva de botton-up approach ${ }^{10}$, quer dizer, deve partir dos

${ }^{8} \mathrm{O}$ processo da Descentralização em Moçambique foi uma iniciativa do governo moçambicano, contudo, contou com a presença dos doadores, tornando-se muitas vezes como uma das prioridades essenciais para os doadores que já atuavam em Moçambique, posto que muitas das vezes foram acusados de pretenderem conduzir este processo. Estes doadores foram: a Comissão Europeia, a USAID, o Banco Africano de Desenvolvimento, o Banco Mundial, os governos da Noruega, da Suécia, da Holanda, da Alemanha, da Áustria, da Bélgica, do Canadá, da Dinamarca, da Espanha, da Finlândia, da França, da Irlanda, da Itália, de Portugal, da Suíça e do Reino Unido. Estas instituições e países contribuíram e até hoje contribuem sobremaneira no apoio ao orçamento do Estado e ao desenvolvimento em Moçambique.

${ }^{9}$ O processo da descentralização culminou com a aprovação de 33 autarquias, para as primeiras eleições autárquicas, pois se tratava de 23 cidades (Pemba, Montepuez, Lichinga, Cuamba, Nampula, Angoche, IIha de Moçambique, Nacala, Quelimane, Gurue, Mocuba, Tete, Chimoio, Manica, Beira, Dondo, Inhambane, Maxixe, Xai-Xai, Chibuto, Chókwe, Matola e Maputo) e 10 vilas (Mocímboa da Praia, Metangula, Monapo, Milange, Moatize, Catandica, Marromeu, Vilankulo, Mandlakaza e Manhiça).

${ }^{10}$ Esta abordagem parte da análise das redes decisórias que têm lugar ao nível dos governos locais, onde os atores envolvidos se enfrentam com os atores do governo central a quando da implementação de políticas, sem conferir um papel determinante às estruturas pré-existentes (relações de causa e efeito entre o governo central e o governo local tomando como pressuposto a hierarquia dentro do poder político). 
Artigo original

Hegemonia - Revista Eletrônica do Programa de Mestrado em Direitos Humanos, Cidadania e Violência/Ciência Política do Centro Universitário Unieuro

ISSN: 1809-1261

UNIEURO, Brasília, número 26, Janeiro a Junho de 2019, pp. 152-173.

Governos Locais ou órgãos do poder local para o governo central e não o contrário. É por este facto que Faria \& Chichava (1999: 6) argumentam que a "Descentralização deve começar pela base, como por exemplo, através da eleição local dos seus representantes na comunidade ou no bairro e assim sucessivamente até ao topo, o que na prática não acontece”.

Portanto, o Estado moçambicano optou por abrir-se para a Descentralização de caráter gradual do poder central aos níveis mais baixos (mantendo o controlo a nível central). Por conseguinte, vislumbra-se aqui uma oportunidade de entrada de novos atores tanto democraticamente eleitos e não, num cenário político bastante heterogéneo.

Por conseguinte, estes aspectos foram favoráveis à criação da Política e Estratégia da Descentralização em Moçambique através da resolução no 40/2012 de 20 de dezembro, que visa promover a participação dos cidadãos, comunidades, autarquias locais e outros atores na governança local, melhorar o desempenho da administração local do Estado e da administração autárquica, por meio de mecanismos que conduzam à eficácia e eficiência na prestação de serviços, e promover a convergência e interação entre as diversas formas de Descentralização democrática, o empoderamento das comunidades e desconcentração, como movimentos coordenados visando à promoção do desenvolvimento local e bem-estar das populações.

Neste sentido, como aludido acima, o contexto do surgimento da política da Descentralização em Moçambique e, portanto, dos Governos Locais é complexo, pois o país estava assolado por uma grande crise econômica desde década 80, o país estava a sair duma guerra civil dos 16 anos que reduziu a economia do país abaixo dos países vizinhos.

Por isso, a implantação da nova Constituição de 1990, a assinatura do Acordo Geral de Paz em Roma (1992) que deu fim à guerra civil, as primeiras eleições democráticas e multipartidárias de outubro de 1994 , a inculcação da lei $3 / 94^{11}$ posteriormente revogada pela lei $2 / 97^{12}$, que cria o quadro

\footnotetext{
${ }^{11}$ Lei que aprova o quadro institucional dos distritos municipais.

${ }^{12}$ Lei que aprova o quadro jurídico para implantação das autarquias locais.
} 
Artigo original

Hegemonia - Revista Eletrônica do Programa de Mestrado em Direitos Humanos, Cidadania e Violência/Ciência Política do Centro Universitário Unieuro

ISSN: 1809-1261

UNIEURO, Brasília, número 26, Janeiro a Junho de 2019, pp. 152-173.

jurídico legal para a implantação das autarquias locais ao abrigo do número 1 do artigo 135 da constituição de 1990, foram fatores favoráveis para a criação dos Governos Locais em Moçambique, que são de fato e de júri instrumentos fundamentais na manutenção da democracia em Moçambique.

2. O Papel dos Governos Locais no Contexto da Governação em Moçambique

Sendo Moçambique, um país unitário e descentralizado, o seu governo não conseguiria de per si, dar respostas às demandas de todos os serviços públicos, e houve necessidade de fato da transferência de poderes a outros órgãos inferiores independentes que pudessem ao nível local continuar os ensejos do Estado na participação dos cidadãos na satisfação das suas próprias necessidades e na escolha dos seus representantes.

Neste sentido, a criação dos Governos Locais ou Autarquias em Moçambique foi um meio de que o país se serviu para descentralizar o poder e que de certo modo contribuiu não só para o desenvolvimento e manutenção da democracia, como também para o envolvimento massivo das populações na tomada de decisões da vida pública.

Em conformidade com o preceituado no número 2 do artigo 1 da lei 2/97 de 18 de fevereiro, as Autarquias Locais são "pessoas coletivas dotadas de órgãos representativos que prosseguem os interesses das populações da respectiva circunscrição territorial, sem prejuízo dos interesses nacionais e da participação do Estado". Neste sentido, as Autarquias Locais representam os municípios (vilas e cidades) e as povoações (sedes do posto administrativo).

No caso moçambicano, as Autarquias Locais não são de per si um processo novo introduzido pela lei 2/97, pois elas já existiam no período colonial, apesar de o modelo adoptado agora não ser o mesmo que aquele. Nesse período, elas tinham um papel reduzido, representando sobremaneira os interesses da administração do Estado colonial, não possuindo um carácter autônomo como hoje em dia. 
Artigo original

Hegemonia - Revista Eletrônica do Programa de Mestrado em Direitos Humanos, Cidadania e Violência/Ciência Política do Centro Universitário Unieuro

ISSN: 1809-1261

UNIEURO, Brasília, número 26, Janeiro a Junho de 2019, pp. 152-173.

Em conformidade com o preceituado no número 2 do artigo 272 da Constituição da República de Moçambique (2004), as Autarquias Locais "são pessoas coletivas públicas, dotadas de órgãos representativos próprios, que visam à prossecução dos interesses das populações respetivas, sem prejuízo dos interesses nacionais e da participação do Estado”.

Neste sentido, as Autarquias Locais, sendo pessoas coletivas de direito público, correspondem ao agregado formado pelos residentes em certa circunscrição do território nacional, de modo que os interesses comuns resultantes da vizinhança sejam prosseguidos por órgãos próprios dotados de autonomia dentro dos limites da lei.

Com a introdução da Descentralização em Moçambique, e com a previsão legal da existência dos Governos Locais (municípios), houve criação das Autarquias locais nos distritos. Em conformidade com Cistac (2001: 6),

a administração das Autarquias Locais é confiada a dois tipos de órgãos: um órgão deliberante e representativo: a Assembleia Municipal ou de Povoação e órgãos executivos: o Conselho Municipal ou de Povoação e o Presidente do Conselho Municipal ou de Povoação.

A criação dos Governos Locais é harmónica com a divisão administrativa e territorial do país, onde já existe o aparelho administrativo. Destarte, a sua introdução na estrutura do Estado com as suas redes de relações e interações fica de facto mais complexa do que era antes. Atualmente, os Governos Locais subsistem, posto que, estão ligados ao perfil político que o país adoptou e segue de certa forma, as orientações e padrões internacionais na tentativa de se manter o sistema democrático vigente.

Em conformidade com o previsto nos números 1 e 2 do artigo 4 da lei 2/97, as atribuições das Autarquias Locais

respeitam os interesses próprios comuns e específicos das populações respectivas e designadamente, desenvolvimento econômico e social local; meio ambiente, saneamento básico e qualidade de vida; abastecimento público; saúde; educação; cultura, tempos livres e desporto; política da autarquia, urbanização, construção e habitação. 
Artigo original

Hegemonia - Revista Eletrônica do Programa de Mestrado em Direitos Humanos, Cidadania e Violência/Ciência Política do Centro Universitário Unieuro

ISSN: 1809-1261

UNIEURO, Brasília, número 26, Janeiro a Junho de 2019, pp. 152-173.

Nesta lógica, a prossecução das atribuições das Autarquia Locais é feita de acordo com os recursos financeiros ao seu alcance e respeita a distribuição de competências entre os órgãos autárquicos e os de outras pessoas coletivas.

Em conformidade com Weimer e Carrilho (2017), nem todas as responsabilidades acima referidas foram traduzidas em funções devolvidas com os recursos correspondentes. Até agora, os Governos Locais executam as seguintes funções principais: organização e construção de mercados; licenciamento de atividades económicas locais; gestão de terrenos municipais, incluindo licenças de Direito de Uso e Aproveitamento da Terra (DUAT) e licenças de construção; construção e manutenção de estradas; gestão de resíduos sólidos; polícia municipal; e gestão de cemitérios.

O gradualismo que se imprimiu ao processo da Descentralização concorreu para o aumento do número de municípios, de trinta e três em 1997, para quarenta e três em 2008 e para cinquenta e três em 2013. O outro gradualismo que aconteceu nesse período é ligado "à transferência gradativa de funções e recursos atualmente detidos pelos órgãos locais do Estado, quer dizer, pelo governo, para os municípios, especialmente no campo do ensino primário e da saúde, mediante solicitação e de acordo com o estipulado por decreto para essa transferência” (WEIMER \& CARRILHO, 2017: 63).

Qual foi o critério da escolha das primeiras Autarquias Locais? Em conformidade com o previsto na lei 2/97, foram usados dois critérios para o efeito: o fator geográfico e o critério da aplicação do previsto na lei. Nesta acepção, em conformidade com o número 2 do artigo 5 deste dispositivo legal, deve-se tomar em conta: “os fatores geográficos, demográficos, económicos, sociais, culturais e administrativos; os interesses de ordem nacional ou local em causa; as razões de ordem histórica e cultural; a avaliação da capacidade financeira para a prossecução das atribuições que lhes estiverem cometidas".

Portanto, a lógica do gradualismo fundamentou-se de certa forma em fatores reais. O fator geográfico estava ligado à localização das vilas propostas, uma em cada província; o fator demográfico tinha como base o número dos cidadãos eleitores apurados no recenseamento geral da população em 1994; o fator económico ligava-se à capacidade de realização de atividades económicas (produção e 
Artigo original

Hegemonia - Revista Eletrônica do Programa de Mestrado em Direitos Humanos, Cidadania e Violência/Ciência Política do Centro Universitário Unieuro

ISSN: 1809-1261

UNIEURO, Brasília, número 26, Janeiro a Junho de 2019, pp. 152-173.

comercialização) dos sectores familiar e empresarial; os fatores social e cultural alicerçavam-se na capacidade financeira avaliada e representada pelo grau de dependência de cada vila em relação a subsídios do Estado ao respectivo orçamento. Destarte, além destes fatores legais, há a considerar "a capacidade das infraestruturas para instalação dos serviços e habitação da administração pública em cada vila e o facto de a administração das vilas encontrar-se totalmente integrada na administração do distrito" (CISTAC, 2001: 23).

A despeito de o gradualismo ter sido concebido pelo governo para a implantação da Descentralização em Moçambique, este foi tido como uma combinação do partido no poder (Frelimo), uma vez que nas áreas rurais onde o partido obteve uma minoria dos votos nas primeiras eleições gerais de 1994, elas não foram qualificadas como autarquias, somente as áreas urbanas onde os resultados das eleições gerais tinham revelado maior apoio para o partido no poder é que foram confiadas como autarquias (CISTAC, 2001; CHIZIANE, 2011).

Contudo, alguns autores como Chiziane (2011: 54), criticaram o "princípio do gradualismo" defendendo que este princípio estabelecido pelo legislador

\footnotetext{
limita sem dúvida a afirmação, o desenvolvimento do princípio constitucional do poder local, limita a participação de todos os cidadãos na promoção democrática do desenvolvimento da sua comunidade, bem como priva os cidadãos de terem as mesmas oportunidades de aprofundamento e consolidação da democracia, através da participação nas eleições autárquicas.
}

Em conformidade com Cistac (2001: 25), o processo de Descentralização em Moçambique deverá fazer face a dois desafios opostos. "Por um lado, as Autarquias Locais deverão passar por um processo rasteiro de 'recentralização’ empreendido pelo Estado desde o começo dos anos 2000, e lutar pelo reforço da sua própria autonomia".

Apesar de a tendência da recentralização não ser um fenômeno típico de Moçambique, já existe em alguns países como a França, e a sua lógica apareceu também, no processo de desconcentração e, mais particularmente, no que concerne ao processo de constituição dos conselhos 
Artigo original

Hegemonia - Revista Eletrônica do Programa de Mestrado em Direitos Humanos, Cidadania e Violência/Ciência Política do Centro Universitário Unieuro

ISSN: 1809-1261

UNIEURO, Brasília, número 26, Janeiro a Junho de 2019, pp. 152-173.

locais. No caso de Moçambique, os seus efeitos podem-se fazer sentir aos níveis financeiros ${ }^{13}$, administrativo ${ }^{14}$ e do controlo ${ }^{15}$.

Em Moçambique os Governos Locais desempenham um papel preponderante para o desenvolvimento local e são um catalisador fundamental na legitimação e manutenção da democracia, onde fazem uma aproximação dos cidadãos por um lado aos centros de tomada de poder e por outro lado no aprofundamento da democracia.

Os Governos Locais, juntamente com as Assembleias Municipais não só consolidam a democracia como também satisfazem as necessidades das comunidades onde estão inseridas, no sentido de estabelecerem mecanismos essenciais para não só fiscalizar a ação de cada membro que integra o cenário político, como também de monitorar a execução das políticas públicas que foram concebidas em função do alcance do desenvolvimento socioeconômico dos distritos onde elas se situam.

Em conformidade com Weimer e Carrilho (2017:193), as Autarquias Locais são um dos "principais promotores da mudança no sentido da Descentralização e devolução, respectivamente, quer individual, quer coletivamente, através do seu organismo coordenador, que é a Associação Nacional dos Municípios de Moçambique”.

\footnotetext{
13 O financiamento das transferências de competências é realizado por dotações orçamentais e não pela criação de receitas fiscais próprias às autarquias locais. Este mecanismo institui uma verdadeira dependência material das autarquias locais em relação ao Estado para o exercício das competências transferidas, continuando o Estado a controlar as atividades das autarquias locais por meio do seu financiamento orçamental.

14 O Estado moçambicano, por decreto de Conselho de Ministros (Decreto n. ${ }^{\circ}$ 51/2004, de 1 de dezembro) impôs os modos de organização dos serviços técnicos e administrativos das autarquias locais, quer dizer, a autonomia administrativa das autarquias viu-se amputada da sua liberdade para se auto organizar.

${ }^{15}$ Este nível de recentralização pressupõe a introdução da tutela revogatória que é a faculdade da entidade tutelar revogar os atos administrativos praticados pelos órgãos das autarquias locais. Esta forma de tutela não existia na legislação aprovada na origem do processo de descentralização e foi introduzida pela Lei n. ${ }^{\circ}$ 6/2007, de 9 de fevereiro que prevê um recurso junto dos órgãos de tutela.
} 
Artigo original

Hegemonia - Revista Eletrônica do Programa de Mestrado em Direitos Humanos, Cidadania e Violência/Ciência Política do Centro Universitário Unieuro

ISSN: 1809-1261

UNIEURO, Brasília, número 26, Janeiro a Junho de 2019, pp. 152-173.

Deste modo, nos municípios, o executivo e os munícipes desempenham um papel essencial na consolidação da governação, posto que há um sentimento de pertença do poder entre eles, fazendo com que haja um aumento significativo da participação da sociedade nas eleições para os governos locais. Portanto, como as Autarquias locais possuem pessoas democraticamente eleitas e legitimadas, há sempre nelas um espaço para o reconhecimento do multipartidarismo, daí a sua necessidade como promotores da Descentralização democrática.

3. Leitura Crítico-reflexiva das Eleições dos Governos Locais que Moçambique

Desde a concepção da lei 3/94 que em seguida foi revogada a favor da lei 2/97, lei que estabelece o quadro jurídico para implantação das autarquias locais, Moçambique até agora viveu 4 eleições Autárquicas para a escolha dos governos municipais.

Em 1998 as primeiras eleições municipais foram boicotadas pelo maior partido da oposição, a Renamo, e pelos outros partidos devido ao deficiente recenseamento eleitoral e deveras pelo critério usado para a seleção das vilas e cidades que foram elevadas à categoria de município. Neste sentido, o fluxo médio às urnas foi muito baixo, equivalente a 15\%. Este indicador denota de certa maneira que a não comparência da oposição deu vantagem aos candidatos da Frelimo que foram todos eleitos como presidentes de todos os municípios que então existiam, ganhando uma maioria de lugares nas Assembleia municipais em 27 dos 33 municípios existentes. Os restantes seis municípios foram ganhos pelos candidatos de pequenos partidos da oposição e grupo de cidadãos que conseguiram de certa forma uma representação mínima nas assembleias municipais de então.

Em 2003, tendo se realizado as segundas eleições municipais, nos 33 municípios com a participação de todos os partidos políticos, a oposição ganhou algumas presidências de municípios, incluindo a da segunda maior cidade do país, a província da Beira. A média de afluência às urnas aumentou para 28\% e isto permitiu que pela primeira vez, partes do território fossem administradas por políticos não filiados ao partido Frelimo. Esta experiência foi muito significativa para 
Artigo original

Hegemonia - Revista Eletrônica do Programa de Mestrado em Direitos Humanos, Cidadania e Violência/Ciência Política do Centro Universitário Unieuro

ISSN: 1809-1261

UNIEURO, Brasília, número 26, Janeiro a Junho de 2019, pp. 152-173.

Moçambique, pois a questão da descentralização, que implica não só a partilha do poder, mas também a concessão do poder aos governos locais foi posta na prática.

Em conformidade com Nuvunga (2012: 281), apesar de a média de afluência às urnas ter variado de 28\% em relação às de 1998, "houve uma baixa percentagem de 15\% na Cidade de Nampula, e 46\% em Mocímboa da Praia e 47\% em Moatize, nas províncias de Cabo Delgado e de Tete, respectivamente".

As terceiras eleições municipais tiveram lugar em 2008, onde 10 vilas tinham sido elevadas à categoria de município, aumentando o número de municípios de 33 em 2003 para 43 neste ano. Portanto, a média de afluência às urnas aumentou significativamente para 46\%, que certa forma constituiu um aumento substancial, se comparado com a média percentual de $28 \%$ para as eleições anteriores.

No mesmo diapasão, Nuvunga (2012) constata que estas eleições tiveram uma situação de uma oposição anterior enfraquecida e dividida onde surge o Movimento Democrático de Moçambique (MDM) encabeçado por Deviz Simango, como candidato independente na cidade da Beira, na sequência do seu afastamento na Renamo. Destarte, as taxas de afluência foram desde baixas - 31\% em Cuamba (Niassa) e 33\% no Alto Molócuè (Zambézia) - a relativamente elevadas - 71\% em Mocímboa da Praia (Cabo Delgado) e 68\% em Ulônguè (Tete).

Foi por estes fatos que a Frelimo recuperou o poder na maior parte dos municípios que tinha anteriormente perdido, exceto na Beira, denotando de certa forma que em termos de Descentralização do poder, elas revelaram que a oposição ganhou mais espaço, havendo mais partilha do poder.

Em dezembro de 2011, houve um fator inédito, que deu lugar à realização das eleições intercalares em três municípios (Quelimane, na Zambézia; em Cuamba, no Niassa; e em Pemba, em Cabo Delgado), onde só concorreu a Frelimo e o MDM, e a Renamo não participou nelas, pois na altura ela bradava pela revisão da lei eleitoral. Nesta lógica, a afluência às urnas foi relativamente baixa, 27\% em Quelimane onde ganhou o MDM, 15\% em Cuamba e 18\% em Pemba, que estes últimos foram ganhos pela Frelimo. 
Artigo original

Hegemonia - Revista Eletrônica do Programa de Mestrado em Direitos Humanos, Cidadania e Violência/Ciência Política do Centro Universitário Unieuro

ISSN: 1809-1261

UNIEURO, Brasília, número 26, Janeiro a Junho de 2019, pp. 152-173.

Em 2013, realizando-se as quartas eleições municipais, inculcou-se mais a essência da Descentralização, aumentando-se para 53 os municípios ao nível nacional. No entanto, houve um fator inédito que consistiu na não participação nas eleições do maior partido da oposição, a Renamo. As razões para a não participação deste partido são as mesmas anteriormente avançadas.

Continuou ainda a partilha do poder, onde as três maiores províncias do país (Beira, Quelimane e Nampula), conhecidas como os maiores círculos eleitorais do país fossem ganhas pelo (MDM). A média de afluência às urnas manteve-se de 46\% como nas últimas eleições, contudo continuando abaixo de 50\% verificado também nas eleições presidenciais de 2009 e 2014 .

No geral, as quatro eleições municipais que Moçambique viveu, as mudanças sucessivas de poder de um para o outro partido em alguns municípios, foram de certa forma, incentivos muito fortes para a inculcação e consolidação das eleições como essencial instituição da democracia representativa não só ao nível central, como também para o nível local. Apesar de estas quatro eleições dos governos locais terem sido realizadas em pleno contexto de gradual Descentralização, pode-se vislumbrar de certa forma que a inculcação do poder aos governos locais é um instrumento significativo para a manutenção da democracia em Moçambique, sendo eles o instrumento para a sua materialização.

Três dimensões de análise são essenciais para o medir a dimensão da democracia nas 4 eleições dos governos locais em Moçambique: a Competição Eleitoral, a Legitimidade das Eleições e a Participação Politica.

A dimensão da Competição Eleitoral constitui um requisito essencial para que as pessoas possam ter alternativas na escolha do candidato que lhes representa. Schumpeter (1961) afirma que a competição eleitoral está pautada na forma de disputa da classe política, inserida no modo de seleção de governantes da democracia representativa, que busca a prevalência do voto popular para controlar o aparato público. Assim, o conceito de competição eleitoral está conectado à luta entre elites políticas que devem se adaptar às regras eleitorais na busca dos cargos públicos.

Em Moçambique, esta dimensão é alicerçada pelos dispositivos legais que permitem com que esta competição tenha lugar. Neste sentido, através do quadro legal existente, vislumbra-se uma 
Artigo original

Hegemonia - Revista Eletrônica do Programa de Mestrado em Direitos Humanos, Cidadania e Violência/Ciência Política do Centro Universitário Unieuro

ISSN: 1809-1261

UNIEURO, Brasília, número 26, Janeiro a Junho de 2019, pp. 152-173.

competição eleitoral pluralista para os detentores do poder local para a presidência do Conselho Municipal e para as Assembleias Provinciais. Neste sentido, a competição eleitoral abre também o caminho para permitir que "grupos de cidadãos proponham listas de candidatos para concorrerem às eleições para as assembleias municipais. Há, pois, mecanismos de jure em funcionamento para adequada participação eleitoral pluralista" (CISTAC, 2001: 65).

A segunda dimensão é concernente à Legitimidade das Eleições e consiste em todos os concorrentes concordarem de forma passiva os resultados das eleições, quer dizer, deve existir o respeito pelas regras de jogo, onde em conformidade com Huntington (1991), todos devem aceitar imediatamente o resultado, reconhecer a derrota e respeitarem uma entrega pacífica do poder. O não cumprimento destes requisitos mínimos, a legitimidade eleitoral fica posta em causa.

Um outro elemento que secunda a legitimidade das eleições é que as eleições sejam transparentes, livres e justas. Contudo, em Moçambique,

\footnotetext{
tanto as eleições nacionais como as autárquicas se realizam num contexto de desconfiança uma característica constante das relações entre a Frelimo e a Renamo desde as negociações de paz de Roma (1994). A desconfiança durante a implementação das disposições do Acordo Geral de Paz assinado em Roma permanece e continua a ter um impacto vital em todas as questões eleitorais, desde a legislação eleitoral até à realização das eleições e validação dos seus resultados, passando pelo registo dos eleitores (NUVUNGA, 2012: 291).
}

Esta contestação da legitimidade das eleições fez com que a oposição não aceitasse e nem reconhecesse os resultados de todas as 4 eleições dos governos locais, exigindo desta feita a sua total anulação. Contudo, a Frelimo, nos municípios onde perdeu, aceitou com facilidade, cedendo desta feita o poder à oposição.

A última dimensão em análise é a Participação Política que constitui um instrumento legal onde se cedem espaços para que todos participem na inculcação da democracia, igualdade de oportunidades, relativamente ao sufrágio, organização de partidos políticos e do seu direito a concorrerem às eleições. 
Artigo original

Hegemonia - Revista Eletrônica do Programa de Mestrado em Direitos Humanos, Cidadania e Violência/Ciência Política do Centro Universitário Unieuro

ISSN: 1809-1261

UNIEURO, Brasília, número 26, Janeiro a Junho de 2019, pp. 152-173.

Huntington e Nelson (1976) concebem participação política como um conjunto de atividades realizadas por cidadãos privados que buscam, de modo mais ou menos direto, influenciar a seleção dos funcionários governamentais e/ou as ações que eles tomam. Neste sentido, trata-se de uma atividade realizada por cidadãos privados com o objetivo de influenciar a tomada de decisão do governo.

A despeito da ambiguidade do conceito de Participação Política, em Moçambique, refere-se que ela consiste na afluência da população às urnas e na sua participação nos partidos da oposição. Nestas 4 eleições, a participação política foi maior na população adulta, onde podiam eleger através do voto, os seus dirigentes e/ou representantes ou mesmo eles de per si se candidatarem às eleições. Esta participação política da população rompeu com a abordagem top-down, sendo desta vez a população a eleger os seus representantes.

A despeito de toda esta abordagem e com as sucessivas mudanças de poder de um para outro partido em alguns municípios nas 4 eleições do Governos Locais, vislumbra-se de certa forma que elas criaram de certa forma alguns incentivos não só para a consolidação das eleições como instituição essencial da implementação da democracia representativa, mas também como garante para a manutenção da democracia tanto ao nível local como ao nível nacional.

\section{Conclusão}

Este artigo denotou que a experiência moçambicana dos Governos Locais tem sido marcada por um lado, pelo forte aperfeiçoamento institucional e por outro, pelo complexo sistema de vínculos intergovernamentais entre o governo central e o local. Este aperfeiçoamento e/ou inovação surgiram desde a concepção do multipartidarismo e posteriormente vincado pelas leis sucessivas que deram importância ao papel dos Governos Locais na manutenção da democracia em Moçambique.

A escolha da temática sobre o papel dos Governos Locais na manutenção da democracia em Moçambique visou compreender a sua importância não só ao nível local, como também ao nível 
Artigo original

Hegemonia - Revista Eletrônica do Programa de Mestrado em Direitos Humanos, Cidadania e Violência/Ciência Política do Centro Universitário Unieuro

ISSN: 1809-1261

UNIEURO, Brasília, número 26, Janeiro a Junho de 2019, pp. 152-173.

nacional ao concebê-los como órgãos democraticamente eleitos que asseguram a participação dos cidadãos na solução dos problemas próprios da sua comunidade em prol do desenvolvimento local. Destarte, eles além de consolidarem a democracia, satisfazem também as necessidades das comunidades onde estão inseridos, no sentido de estabelecerem mecanismos essenciais para não só fiscalizar a ação de cada membro que integra o cenário político, como também monitorar a execução das políticas públicas que foram concebidas em função do alcance do desenvolvimento socioeconômico dos distritos onde elas se situam.

Esta pesquisa mostrou que a instituição dos Governos Locais é recente em Moçambique como alude a leitura crítico-reflexiva das eleições dos Governos Locais. Contudo, estas quatro eleições que tiveram lugar em pleno contexto de consolidação da democracia e da Descentralização gradual são um apanágio de que Moçambique é um país com uma democracia em crescimento e em plena solidificação. Apesar de a participação dos eleitores nas eleições ter sido baixa, causada por vários fatores, é jus louvar a preocupação do país em manter e/ou consolidar a democracia e a paz.

Portanto, durante o período em que se institucionalizou os Governos Locais, houve também uma ampla competição eleitoral nas eleições municipais, sob a égide de contínuo domínio da Frelimo aos níveis nacional e local. Sem embargo de a oposição não considerar como legítimas as eleições municipais durante este período, a Frelimo e a comunidade nacional e internacional as considerou como justas e transparentes.

Por conseguinte, salvo a capacidade desigual dos municípios moçambicanos em tomarem dianteira na institucionalização e reconhecimento dos Governos Locais como vetores fundamentais na manutenção da democracia, existem indicações que denotam para mudanças na forma como a democracia local está ocorrendo. Não obstante, o maior envolvimento do governo central e das comunidades locais na manutenção da democracia e do bem-estar da população, em Moçambique ainda não está claro se esta manutenção da democracia será sustentável sem o apoio financeiro e indutor do governo central e de outros organismos exógenos ao governo local. 
Artigo original

Hegemonia - Revista Eletrônica do Programa de Mestrado em Direitos Humanos, Cidadania e Violência/Ciência Política do Centro Universitário Unieuro

ISSN: 1809-1261

UNIEURO, Brasília, número 26, Janeiro a Junho de 2019, pp. 152-173.

Referências Bibliográficas

CHIZIANE, E. (2011). The Trends of recentralization of the administrative power in Mozambique. Universidade Eduardo Mondlane, Imprensa Universitária: Maputo.

CISTAC, G. (2001). Manual de Direito das Autarquias Locais. Livraria Universitária. Universidade Eduardo Mondlane: Maputo.

FARIA, F. \& CHICHAVA, A. (1999). Descentralização e Cooperação Descentraliz̧ada em Moçambique, Documento de Reflexão n. ${ }^{\circ}$ 12, Maastricht, European Centre for Development Policy Management (ECDPM).

FERNANDES, T.M. (2009), O Poder Local em Moçambique: Descentralização, Pluralismo jurídico e legitimação. Afrontamento: Porto.

HUNTINGTON, S. P; NELSON, J. M. (1976). No easy choice: political participation in developing countries. Cambridge, Harvard University Press.

HUNTINGTON, S. P., (1991). The Third Wave: Democratization in the Late Twentieth Century. Norman/London: University of Oklahoma Press.

NUVUNGA A. (2012). Tendências nas Eleições Municipais de 1998, 2003 e 2008, In Bernhard Weimer (org.) Moçambique: Descentralizar o Centralismo. Economia política, Recursos e Resultados. IESE. Maputo.

SCHUMPETER, J. (1961). Capitalismo, Socialismo e Democracia. Rio de Janeiro: Editora Fundo de Cultura.

WEIMER, B. \& CARRILHO, J. (2017). A Economia Política da Descentralização em Moçambique Dinâmicas, Efeitos, Desafios. IESE. Maputo.

Legislação

Boletim da República (1990). Constituição da República de Moçambique, de 2 de Novembro de 1990. I Série-No 44. Imprensa Nacional: Maputo. 
Artigo original

Hegemonia - Revista Eletrônica do Programa de Mestrado em Direitos Humanos, Cidadania e Violência/Ciência Política do Centro Universitário Unieuro

ISSN: 1809-1261

UNIEURO, Brasília, número 26, Janeiro a Junho de 2019, pp. 152-173.

Boletim da República (1994). Lei n. ${ }^{\circ}$ /94 de 13 de setembro. Aprova o quadro institucional dos distritos municipais. I Série n. ${ }^{\circ}$ 37. (Lei dos Distritos Municipais).

Boletim da República (1997). Lei n 02/97 de 18 de fevereiro. Aprova o quadro jurídico para implantação das autarquias locais. I Série. Número 7. Imprensa Nacional: Maputo.

Boletim da República (2004). Constituição da República de Moçambique, de 22 de Dezembro de 2004. I Série-No 51. Imprensa Nacional: Maputo.

Boletim da República (2004). Decreto n. ${ }^{\circ}$ 51/2004 de 1 de dezembro. Aprova o Regulamento de Organização e Funcionamento dos Serviços Técnicos e Administrativos dos Municípios. Suplemento, I Série-Número 48. Imprensa Nacional: Maputo.

Boletim da República (2012). Resolução n. ${ }^{\circ}$ 40/2012 de 20 de dezembro: Aprova a Política e Estratégia da Descentralização, I Série-Número 51. Imprensa Nacional: Maputo.

Boletim da República (2003). Lei no 8/2003 de 19 de maio. Aprova a lei dos órgãos Locais do Estado, I Série, Número 20. Imprensa Nacional: Maputo. 